\title{
Contribuições da literatura para a História da Educação
}

Literature contributions to the History of Education

Contribuciones de la literatura a la Historia de la Educación

\section{Organização}

\author{
Ana Laura Godinho Lima \\ Universidade de São Paulo (Brasil) \\ https://orcid.org/0000-0003-4154-0858 \\ http://lattes.cnpq.br/4941128584192341 \\ alglima@usp.br \\ Roni Cleber Dias de Menezes \\ Universidade de São Paulo (Brasil) \\ https://orcid.org/0000-0001-8661-1328 \\ http://lattes.cnpq.br/2780596138885068 \\ roni@usp.br
}

\section{Apresentação}

Este dossiê parte da premissa de que a literatura tem contribuições preciosas a oferecer para a história da educação. À partida, no que concerne mais de perto ao domínio metodológico, é notável a dilatação - acompanhada em seu aspecto quantitativo pelo que se refere também à diversidade - das fontes e dos objetos propiciados pelas obras literárias para a interpelação do passado educativo realizada pelo historiador. A exploração dessa potencialidade está em íntima consonância com o movimento de renovação historiográfica vindo à tona nas últimas décadas do século $\mathrm{XX}$ no terreno da história tout court e que chega um pouco mais tarde ao domínio da história da educação. Caracterizada em grande medida pelo protagonismo das temáticas de matiz sociocultural, as apropriações realizadas no interior desta última apontam outrossim para novos problemas, os quais terminam por provocar novas abordagens, intensificando o diálogo da história da educação com outras áreas das ciências humanas, especialmente em torno da mobilização de novos repertórios teóricos. 
Em correlação com o movimento assinalado acima, a maior presença da literatura, tomada tanto como fonte quanto como objeto de análise no campo da história da educação, faz-se sentir a partir dos anos 1990 em vários dos veículos de divulgação e escoamento da produção da área. Nas revistas especializadas do campo, surgidas na maior parte naquele decênio e nos seguintes, nas atas dos eventos científicos da área e nas monografias produzidas no interior dos programas de pós-graduação se observam abordagens variadas, que abrangem desde a literatura infantil, passando por perfis de intelectuais da educação e sua vinculação ao campo literário, a produção literária de professores, as dimensões educacionais presentes na obra de escritores, a literatura nas políticas e projetos de alfabetização, a própria história da literatura infantil até os possíveis usos da literatura como fonte para a exploração dos processos de escolarização.

Sintonizado com tais possibilidades, o conjunto de investigações que ora se apresenta visa a exercitar alguns caminhos franqueados pelo uso da literatura como instrumento para a inquirição de relevantes problemas do passado educativo.

Desse modo, se a aproximação com a literatura, no modo como é tentado neste dossiê, denota a forma como os autores e autoras dos trabalhos internalizam a miríade de transformações operadas no interior do campo historiográfico, vale destacar ainda uma faceta relevante que é dada a ver por alguns dos estudos aqui apresentados: o de investigar na literatura da primeira metade do século XX interpretações tanto sociológicas quanto psicológicas sobre o passado educativo, em períodos em que as ciências sociais, pelo menos no Brasil, não contavam ainda plenamente com regimes de produção científicoacadêmicos que se consagrariam na esteira daquele momento histórico a partir da consolidação das universidades em nosso país.

Bem sopesadas tais ancoragens, o dossiê reúne textos que analisam obras literárias tendo em vista a dimensão dos conhecimentos sobre a história e os sujeitos da educação, bem como dos processos pedagógicos e de escolarização que essas obras permitem apreender. As análises incidem sobre títulos que se aproximam dos gêneros: ficção, romance de formação, memórias autobiográficas, livros de leitura para a escola primária. Sensíveis ao modo como incidem no campo historiográfico os problemas relativos à comprovação da veracidade histórica e ao estatuto das fontes, os artigos sustentam a hipótese de que as ficções, as autobiografias e as memórias podem contribuir para a compreensão dos processos de formação, da transformação dos sujeitos, das experiências e práticas escolares, de constituição da profissão docente e dos dispositivos de exclusão e hierarquização social operados no interior da escola.

As análises realizadas tomam as obras literárias como recurso para a produção do conhecimento histórico, relacionando-as com a produção acadêmica da história da educação. Pormenorizadamente, referem-se a diversas questões de interesse para o campo educacional, dentre as quais sobressaem aquelas relativas ao processo de formação dos indivíduos e certos aspectos da cultura escolar. Tratam dos diferentes modos como os sujeitos interagem com as circunstâncias vividas em seu cotidiano e, a partir das próprias vivências, fazem as suas escolhas; como são direta ou indiretamente afetados pelos acontecimentos históricos de maior repercussão e ainda como o acaso produz também os seus efeitos nas trajetórias individuais de formação, na forma de encontros e eventos inesperados. 
Em conjunto, os artigos se referem às práticas e às rotinas escolares, às dificuldades e a falta de sentido de muitas das atividades propostas e das exigências feitas pelos professores na percepção de certos estudantes, inclusive de alguns que se tornaram posteriormente escritores amplamente reconhecidos por seu talento. Discutem o tema do preconceito e do descrédito que pesa sobre parte dos alunos, em especial aqueles que já se encontram marginalizados socialmente. Detêm-se sobre as especificidades da educação destinada às meninas e a formação das mulheres para o exercício da docência.

Em "A autoformação do escritor fora e contra a escola portuguesa: Teixeira de Pascoaes e a sublimação do génio, do Livro de memórias (1928) a Uma fábula (1952)”, as reflexões estão centradas em torno da temática da autoformação do artista. Para tal, recorre-se à análise do processo de formação intelectual do insigne poeta português Teixeira de Pascoaes e, nomeadamente, da maneira como o autor avalia a escolarização oferecida em seu tempo em Portugal, incapaz, em seu julgamento, de assegurar um processo de ensino-aprendizagem para a escrita literária, em particular no que se referia à disciplina de Língua Portuguesa. Veem-se imbricadas na abordagem sobre a autoformação do escritor a tematização das precariedades do processo de escolarização português, imbricação modulada pelas clivagens entre a cultura familiar e a escolar e os diferentes dispositivos que atuam nesse quadro de formação intelectual e de transmissão de saberes, com destaque para o "paradigma" do gênio, em que os atributos tidos como de natureza individual tomados como tecnologia que explicariam a prodigiosidade e a acuidade do labor artístico são reexaminados à luz da teoria sociológica, em e special com o auxílio de repertório oriundo da produção de Norbert Elias.

“'Lectora amiga', Género y experiencia de escolarización en la Argentina de la década de 1930" tece considerações sobre a educação das meninas na Argentina dos anos 1930, em vista das expectativas sociais relativas às mulheres: os traços de personalidade, os cuidados com a aparência, o comportamento em sociedade e as responsabilidades no cuidado do lar e das crianças, entre outros elementos associados à feminilidade. $\mathrm{O}$ artigo realiza uma análise fértil dessas questões a partir da trajetória escolar de uma estudante por meio do exame de seu caderno escolar e do seu livro de leitura empregados no último ano da escola primária, assim como de relatos autobiográficos escritos pela mulher que ela se tornou setenta anos depois de concluir o ensino primário. Um aspecto sugestivo da cultura material escolar tratado no texto diz respeito à existência de duas versões do livro de leitura estudado, El Forjador, da autoria de Luis Arenas, expoente do movimento escolanovista na Argentina. Havia uma versão destinada aos meninos e outra às meninas, cujas diferenças permitem identificar as concepções de gênero tal como de difundiam no cotidiano escolar.

No artigo "O romance Canção de ninar e a relação entre as mulheres, a educação e o trabalho: a Cuca nas vidas femininas desde meados do século XIX”, as autoras se valem de uma obra caracterizada como suspense psicológico para apresentar reflexões sobre as ameaças que ainda hoje pairam sobre as mulheres que buscam conciliar a maternidade e a vida profissional. A partir do livro vencedor do Prêmio Goncourt de literatura francesa de 2016, as autoras mostram de maneira original e convincente como diversos elementos da história da educação das meninas e da profissionalização das mulheres contribuem para a compreensão das razões pelas quais o trabalho das mulheres, em especial aquelas que se tornam mães, tende a não ser reconhecido em sua importância. 
Com seu desfecho trágico, o romance mostra de maneira dramática como o trabalho feminino costuma ser invisibilizado quando se realiza dentro de casa e consiste em cuidar de outras pessoas ou a ser considerado como supérfluo quando se realiza fora de casa, como se fosse uma forma de distração da mulher, uma fuga da sua verdadeira obrigação, a de cuidar das crianças. É o que leva as mães que trabalham a serem responsabilizadas por todo tipo de dano ou sofrimento que seus filhos venham a sofrer.

Em “'Isto aqui não é escola, é zoológico. Lá estão os animais”: Morte em tenra idade de Jonathan Kozol e as injustiças e violências promovidas pelo sistema escolar americano na década de 1960", são focalizadas questões diretamente associadas às relações conflituosas entre professores e alunos, dadas a ver a partir da reconstituição da atmosfera de uma escola segregada do subúrbio de Boston, nos Estados Unidos. A análise leva em consideração o período conturbado em que o livro é publicado, 1960, marcado pela luta dos negros estadunidenses por direitos civis e pelas reações suscitadas pela participação dos EUA na Guerra do Vietnã. O racismo e as práticas discriminatórias a ele correlatas integram, assim, o caudal em que Kozol constrói suas memórias de cunho autobiográfico e que são aproveitados pelo artigo em tela para problematizar o temário da violência simbólica no interior da escola, mediatizado por uma discussão teóricametodológica acerca do aproveitamento de uma produção literária alicerçada na evocação das memórias escolares com o fito de testar suas potencialidades enquanto dispositivo de interpretação da realidade histórica, social e psicológica do passado educativo.

"O romance de formação da professora: contribuições da literatura para pensar a história da educação", por sua vez, examina as condições históricas de formação das professoras e do exercício da docência na primeira metade do século XX no Brasil por meio do exame de duas obras literárias: O calvário de uma professora (1928) e Clarissa (1933). O primeiro consiste em um romance autobiográfico que apresenta um rico testemunho sobre a formação e o exercício profissional de uma professora normalista em São Paulo durante a Primeira República. A análise evidencia outros aspectos das restrições enfrentadas pelas mulheres em suas oportunidades de formação, escolha e exercício da profissão. A docência apresentava-se como uma alternativa para as mulheres, mesmo assim era difícil para elas alcançarem as posições mais elevadas na carreira. As professoras quase invariavelmente se viam submetidas a autoridade de colegas homens, num contexto no qual o mérito pesava pouco na atribuição dos cargos. Clarissa(1933) oferece um retrato da jovem professora em formação feito pelo escritor Érico Veríssimo, que não sofreu na própria pele os desafios enfrentados pelas professoras, mas acompanhou com interesse as intensas discussões sobre o tema da educação nos anos 1930 no país e expressou no romance a sua própria visão dos problemas da escola e as suas esperanças depositadas na renovação das práticas escolares, as quais se aproximavam das propostas veiculadas no Manifesto dos Pioneiros da Educação Nova (1932).

“"Fala pouco e bem, ter-te-ão por alguém: escolarização, moralização e produção de sentido a partir das memórias de José Lins do Rego e Graciliano Ramos (Brasil, 19301945)", revela a tentativa de, ao explorar dois romances de formação baseados em escritos de natureza autobiográfica - Doidinho (1933) e Infância (1945) - de autoria, respectivamente, de José Lins do Rego e Graciliano Ramos, problematizar a escolarização do país na primeira metade do século XX em termos do sentido apreendido pelos indivíduos 
daquele tempo a propósito da escola, seus rituais, dos saberes ensinados e da própria função cumprida por estes no cotejamento com os dramas reais da vida concreta. Importante assinalar que os indivíduos a que se faz menção ganham a feição, tendo em vista os expedientes de criação literária dos romancistas, de figuras arquetípicas da sociedade em que transcorre a trama, propondo uma intelecção do real não apenas a partir do recurso das memórias dos autores, mas, adicionalmente, tais memórias compõem um quadro complexo, fruto da junção de distintas temporalidades, a do "eu" narrador e a do "ele" personagem, em que a dimensão de cariz psicológico, tanto aquela que caracteriza mais estritamente o enredo quanto aquela empregada pelos literatos para recriar a atmosfera de seus respectivos passados escolares, são exploradas no artigo de modo a enriquecer a abordagem histórica acerca das vicissitudes da afirmação da instituição escolar no país.

A leitura em conjunto dos artigos que compõem esse dossiê, no qual as questões educacionais são examinadas a partir da literatura e na interface com a história da educação, evidencia a fertilidade desse encontro. A elaboração literária dos personagens nas obras consideradas favorece uma aproximação à experiência pessoal dos sujeitos implicados na relação pedagógica: as impressões iniciais da criança que vai pela primeira vez à escola; a indignação do estudante que não se sente respeitado pelos seus professores ou o desânimo daquele que não consegue compreender o sentido dos deveres que lhe são impostos; as relações que, por seu lado, as professoras e os professores estabelecem com o seu ofício, as dificuldades que encontram e como as enfrentam. Além disso, a caracterização dos espaços, dos tempos e das interações sociais apresentadas nos livros de literatura, quando posta em relação com os conhecimentos produzidos no âmbito da história da educação, permite apreender outros matizes do processo de formação dos indivíduos e da própria existência das escolas em suas circunstâncias sociais e históricas. 